\title{
13. ATMOSPHERIC HEIGHTS OF TELESCOPIC METEORS
}

\author{
L. KoHOUTEK \\ (Astronomical Institute of the Czechoslovak Academy of Sciences, Prague)
}

The heights of sporadic telescopic meteors were observed from three stations, distant from each other $9 \cdot 1,6 \cdot 0$ and $3 \cdot 2 \mathrm{~km}$ respectively, during the Pieštany meteor expedition in the summer of 1960 (Kohoutek, 1967). Three teams of four observers gathered individually data on 1187 meteors, together with 1864 drawings, during the period of 7 nights, August 15-27. Altogether, 189 pairs observed by at least two stations were identified from the complete material. The heights of the respective beginning (b), centre (c) or end (e) points of 159 pairs were determined by means of graphic-numerical analysis.

The parallactic shifts $(\pi)$ at different points of the meteor trajectory, as recorded at the three bases, have been studied. For these statistics only meteors recorded by at least two observers at either station have been chosen. The dispersion of $\pi$ is evidently caused by the real dispersion of meteor heights and by the errors of meteor plotting; the results are compared in Table 1.

\section{Table 1}

$\begin{array}{rcccccccc}\text { St } & \text { Point } & \pi\left(^{\circ}\right) & \sigma_{\text {obs }}\left({ }^{\circ}\right) & \sigma_{\text {err }}\left({ }^{\circ}\right) & \sigma\left(^{\circ}\right) & H_{\pi}(\mathrm{km}) & \sigma(\mathrm{km}) & H(\mathrm{~km}) \\ & & & & & & & & \\ 12 & \mathrm{~b} & 3.92 & 0.64 & 0.58 & \pm 0.27 & 99.8 & \pm 6.8 & 89.0 \\ & \mathrm{c} & 4.10 & 0.66 & 0.37 & 0.55 & 95.5 & 12.8 & 86.9 \\ & \mathrm{e} & 4.76 & 0.78 & 0.71 & 0.32 & 82.3 & 5.4 & 80.1 \\ 13 & \mathrm{c} & 2.68 & 0.70 & 0.68 & - \pm 0.15 & 96.2 & 5.2 & -\end{array}$

Here $\pi=$ the mean parallactic shift of the meteor group, $H_{\pi}=$ the height above sea level corresponding to $\pi, \sigma_{\mathrm{obs}}=$ observed dispersion of $\pi, \sigma_{\mathrm{err}}=$ dispersion resulting from the mean error of one independent value of $\pi, \sigma=$ the real dispersion in degrees and kilometers, respectively. The value of $H$ represents the arithmetic mean of the meteor heights. Our summary contains results from St. 12 only, compared with that from St. 13 (c). The dispersion $\sigma_{\mathrm{obs}}$ determined for the meteors which were observed at St. 23 (base line $3 \cdot 2 \mathrm{~km}$ only) was comparable with the observing errors and therefore these values have not been used.

The most probable mean heights were obtained as the arithmetic means of $H_{\pi}$ and $H$, i.e. 94,91 and $81 \mathrm{~km}$ for the beginning, centre and end points, respectively (the average corrected absolute magnitude was $M=6 \cdot 3$ ).

The dependence of the heights of individual meteor points on the absolute magnitude 
was analysed in detail (Figure 1). It is concluded that there is negligible height variation with magnitude in the interval from 4.5 to 8 abs. mag.

The mean geocentric velocity, $v_{\infty}$, of meteors of our material was estimated from the theoretical dependence $H\left(v_{\propto}\right)$, which was derived by Hawkins and Southworth (1958) and Jacchia et al. (1965). For the observed centre of the meteor trajectory the values $32.5 \mathrm{~km} / \mathrm{sec}$ and $37.0 \mathrm{~km} / \mathrm{sec}$, respectively, were determined, with an arithmetic mean of $35 \mathrm{~km} / \mathrm{sec}$.

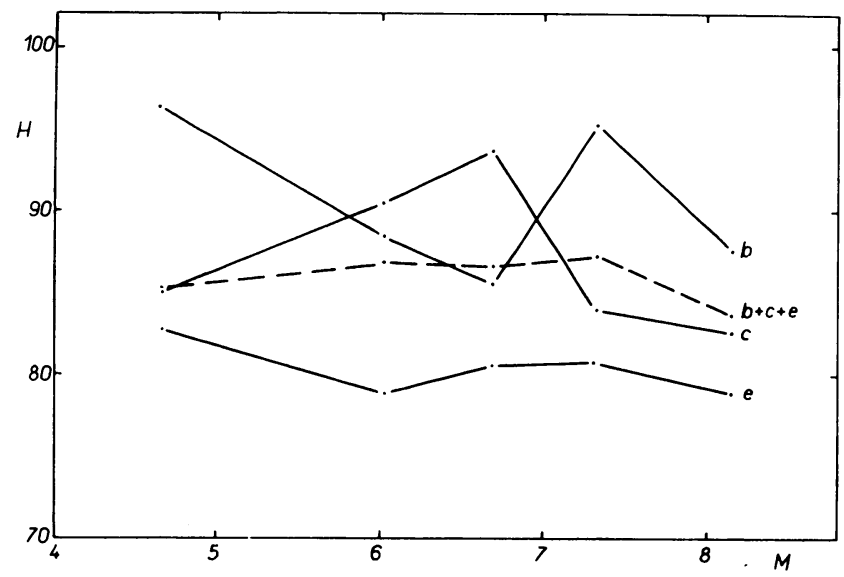

FIG. 1. The dependence of meteor heights (in $\mathrm{km}$ ) on the absolute magnitude for beginning (b), centre (c) and end (e) point.

By making use of (1) the theoretically derived relation (Ceplecha and Padevět, 1961) between the magnitude of a meteoroid and the height at which intense evaporation begins (provided that the beginning of intense evaporation coincides with the height of appearance $H_{\mathrm{b}}$ ), (2) the mean zenith distance of the radiants, $\cos z_{R}=0.66$ (Jacchia et al., 1965), (3) the density of the meteoroids, and (4) the geocentric velocity, we determined the mean radius $r_{0}$ of the particles: $r_{0}=0.50$ and $0.38 \mathrm{~mm}$, for stony and iron meteoroids, respectively. The data mentioned above also permit us to determine approximately the value of the energy $Q$, needed for the heating and evaporating of $1 \mathrm{~g}$ of meteoric matter: $10.5 \times 10^{10} \mathrm{erg} / \mathrm{g}$ and $4.8 \times 10^{10} \mathrm{erg} / \mathrm{g}$ for stony and iron meteoroids, respectively. Öpik (1958) established for stony meteoroids $Q=6.05 \times 10^{10}$ $\mathrm{erg} / \mathrm{g}$, which is the value lying between our present value and that which was derived from our last observations in 1958, $Q=3.5 \times 10^{10} \mathrm{erg} / \mathrm{g}$ (Kohoutek and Grygar, 1962).

The diurnal variation of heights of telescopic meteors is shown in Figure 2. Whilst the $H_{\mathrm{e}}$ value remains practically constant with time (local sidereal time), the $H_{\mathrm{b}}$ value apparently increases. This increase of $H_{\mathrm{b}}$ might be explained from the increase of the mean geocentric velocity of meteors.

Recently Ceplecha (1966) introduced the $k_{\mathrm{b}}$-parameter as a very good criterion for 


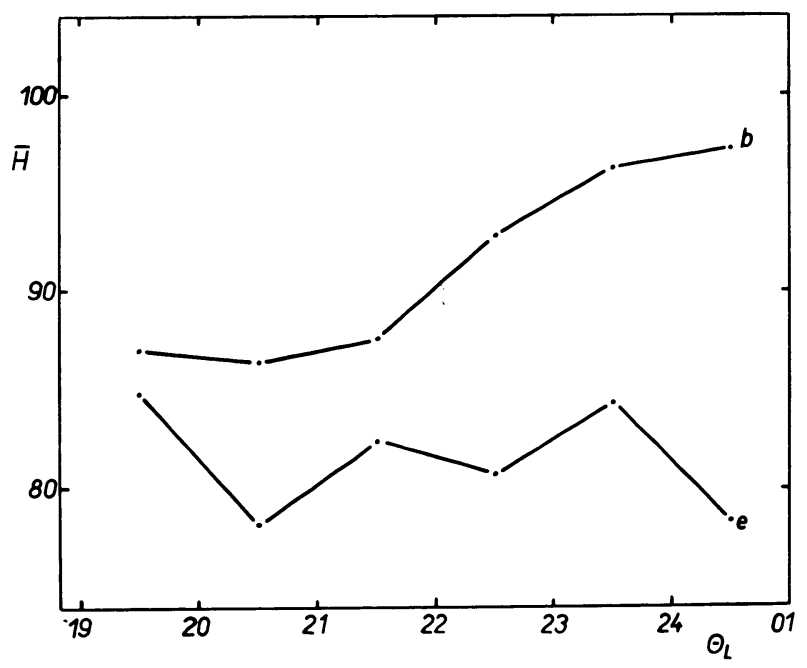

FIG. 2. The course of the diurnal variation of meteor heights: $\bar{H}$-height in $\mathrm{km}, \theta_{\mathrm{I}}=$ local sidereal time in hours.

the estimation of the meteoroid composition. If we know the air density at the beginning of the meteor (adopted $\log \rho_{\mathrm{b}}=-8 \cdot 86$ ) and mean $\cos z_{R}$, we can calculate, for the different values of the $k_{\mathrm{b}}$-parameter, the geocentric velocity from the equation

$$
\log v_{\infty}=\frac{2}{5} k_{\mathrm{b}}-\frac{2}{5} \log \rho_{\mathrm{b}}+\frac{1}{5} \log \cos z_{R} .
$$

Results are given in Table 2.

\section{Table 2}

$\begin{array}{ccc}\text { Group } & k_{b} & v \star(\mathrm{km} / \mathrm{sec}) \\ & 7.8 & 42.6 \\ \text { A } & 7.4 & 29.5 \\ \text { B } & 7.0 & 20.3 \\ \text { C } & 6.6 & 14.1\end{array}$

Unfortunately, we are not able to measure the geocentric velocity for individual meteors; our mean value, $v_{\infty}=35 \mathrm{~km} / \mathrm{sec}$, lies in the middle of the velocity interval corresponding to the group A. In this case, most of telescopic sporadic meteors would have the greatest meteoroid density, short-period orbits with small eccentricities and ecliptical concentration.

\section{References}

Ceplecha, Z. (1966) Bull. astr. Inst. Csl., 17, 347.

Ceplecha, Z., Padevět, V. (1961) Bull. astr. Inst. Csl., 12, 191. 
Hawkins, G.S., Southworth, R. B. (1958)

Smithson. Contr. Astrophys., $2,349$.

Jacchia, L. G., Verniani, F., Briggs, R.E. (1965) Smithson. Contr. Astrophys., $10,1$.

Kohoutek, L. (1967) Bull. astr. Inst. Csl., 18, 171.

Kohoutek, L., Grygar, J. (1962) Bull. astr. Inst. Csl., 13, 9.

Öpik, E.J. (1958) Physics of Meteor Flight in the Atmosphere, Interscience Publishers, New York, Appendix 1-2.

\section{DISCUSSION}

Ceplecha: Values of the $k_{\mathrm{b}}$-parameter used by Kohoutek were derived from the McCrosky-Posen Super-Schmidt meteors with about $+5^{\mathrm{m}}$ as the limit, while the telescopic meteors presented here have the limiting magnitude about $+10^{\mathrm{m}}$. I do not believe that such a big extrapolation would be possible at all.

Kohoutek: It is, of course, true. It is very difficult to extrapolate the results from bright to faint meteors, but, unfortunately, I had no other possibility. 